\begin{tabular}{|c|l|}
\hline Title & A treatise on frequency spectrum of drift ice vel ocity \\
\hline Author(s) & Leppäranta, Matti; Oikkonen, A nnu; Shirasawa, Kunio; Fukamachi, Y asushi \\
\hline Citation & $\begin{array}{l}\text { Cold Regions Science and Technology, 76-77,83-91 } \\
\text { https://doi.org/10.1016/.coldregions.2011.12.005 }\end{array}$ \\
\hline Issue Date & 2012-06 \\
\hline Doc URL & http://hdl.handle.net/2115/49349 \\
\hline Type & article(author version) \\
\hline File Information & CRST 76-77_83-91.pdf \\
\hline
\end{tabular}

Instructions for use 


\section{A treatise on frequency spectrum of drift ice velocity}

Matti Leppäranta ${ }^{1}$, Annu Oikkonen ${ }^{1}$, Kunio Shirasawa ${ }^{2}$ and Yasushi Fukamachi ${ }^{2}$

${ }^{1}$ Department of Physics, University of Helsinki, Helsinki, Finland

${ }^{2}$ Institute of Low Temperature Science, Hokkaido University, Sapporo, Japan

* Corresponding author. Department of Physics, University of Helsinki, P.O. Box 48 (Erik

Palménin aukio 1), FIN-00014 Helsinki, Finland. Tel. +358-9-19151016. Email

matti.lepparanta@helsinki.fi

\section{Abstract}

Sea ice dynamics is examined for the frequency spectra of ice velocity using mathematical models and ice motion data. The data are from the Baltic Sea and Sea of Okhotsk. A general spectrum for linear coupled ice-ocean free drift is derived and analysed. Interior dynamics shows singularity in the Coriolis (inertial) frequency and asymptotic high frequency power law of -2 . In the presence of internal friction the spectrum is expected to evenly fall to zero with frictional resistance increasing above yield level. In the observations, the main spectral peak is wide at the synoptic time scales. The Okhotsk Sea spectra show inertial and tidal signals but they are missing from the Baltic Sea due to very weak tides and shallow depth damping inertial oscillations. Above semidiurnal frequency ice velocity spectra fall in power law of $-5 / 3$, inherited from atmospheric and oceanic dynamics, and at very high frequencies, above $0.5 \mathrm{cph}$ the fall seems to slow down to power law below -1 . The Eulerian ice velocity 
spectrum was higher than the Lagrangian spectrum throughout the entire obtained spectrum $(0.1-5 \mathrm{cpd})$. Theoretical spectra show general agreement with observations except that they have less kinetic energy at very high frequencies and much stronger inertial peak. Thus Eulerian observations are more variable than Lagrangian observations.

Keywords $\quad$ sea ice, kinematics, dynamics, frequency, spectrum

\section{Introduction}

Sea ice motion is forced by winds and ocean currents. It is a granular medium. Each ice floe performs its own individual trajectory, independently in the absence of internal stress. On scales much larger than the floe size, a continuum approximation is commonly assumed. Continuum parcels consist of a large number of ice floes. This large-scale ice is a twodimensional, compressible and non-linear geophysical fluid at the continuum length scale, and consequently the problem and solutions are of general scientific interest. Wind acts as an independent external force, but the motion of ice is closely coupled with the ocean boundary layer (OBL). Momentum is transferred from wind to drifting ice and further to water body, or from geostrophic ocean currents and tidal currents through OBL to ice. The response of drift ice to forcing is dictated by its inertia, rheology and re-distribution of its thickness field. In closely packed fields of ice floes, internal stress is very important and can even prevent the ice from moving, while in open packing the floes drift free with no significant mutual interactions.

The first records of drift ice kinematics are from Nansen (1902). The motion of Fram, crossing the Eurasian side of the Arctic Ocean, was 2\% of the surface wind speed directing 
$30^{\circ}$ to the right from the wind direction. In later years, with accumulated database, empirical corrections for different ice conditions were applied on this relationship (Zubov, 1945), to account for the influence of internal ice stress. Also the variation of the atmospheric and oceanic drag parameters due to stratification of the boundary layers and roughness of sea ice was examined by Rossby and Montgomery (1935). These results could explain some of the observed variability in sea ice drift velocity. The presence of internal stress was known from the beginning (Nansen, 1902) but only in 1950s it was first mathematically formulated, then as a linear viscous law (Laikhtman, 1958). Plastic flow laws, corresponding to the present understanding of drift ice mechanics, were introduced 15 years later (Coon et al., 1974).

In free drift, i.e. in the absence of internal stress, atmosphere-ice-ocean forms a linear system in the first approximation (Shuleikin, 1938; McPhee, 1980; Leppäranta, 1981). Nonlinearities arise due to nonlinear ice-water drag force and momentum advection, which, however, is a minor term. In contrast, plastic drift of closely packed or compact ice fields contains highly nonlinear dynamics (Coon et al., 1974; Pritchard, 1975; Hibler, 1979). Plastic yield of drift ice is quite specific, as it shows no resistance to tension but high, strain-hardening resistance to compression. In the regime between plastic flow and free drift there is a state when interactions between ice floes are due to floe collisions (Shen et al., 1986) but the resulting internal ice stress is then small.

The physics of sea ice drift is fairly well understood (e.g., Leppäranta, 2011), but there are still relevant open questions. A particular problem is scaling of sea ice dynamics and its space-time spectrum. Temporal characteristics of ice drift have been treated in papers about drifter data (e.g., Hibler et al., 1974; Ono, 1978; Thorndike and Colony, 1980; McPhee, 1980; Leppäranta, 1981; Leppäranta and Omstedt, 1990; Schevchenko et al., 2004; Leppäranta et al., 
2009), where the close connection with wind and the presence of Coriolis and tidal signals have been recognised. Inertia of the ice itself shows up only at very high frequencies. Less work has been done on the spatial characteristics of ice drift, and the present knowledge of spatial variability of ice motion is still only qualitative. Thorndike (1986) analysed drift buoy data for correlation structure in longitudinal (along ice motion) and transverse drift directions, and Kheysin (1978), Sanderson (1988) and Richer-Menge et al. (2002) have examined internal ice stress in different length scales. Spatial structures and scales have been discussed by Overland et al. (1995), Marsan et al. (2004), Hutchins and Hibler (2008), Goldstein et al. (2009), Rampal et al. (2009), and Stern and Lindsay (2009).

A better knowledge of scaling dynamics processes is required for research and applications. Comparisons between sea ice velocities from model simulations and Radarsat data have shown that the present models are incapable to produce spatial or temporal scaling laws that match those observed in nature (e.g., Leppäranta et al., 1998; Girard et al., 2009). The time co-ordinate presents a more straightforward problem as it can be approached using the continuum theory, but in spatial scaling one needs to go from a continuum system of ice floes to granular flow and further to interior dynamics of individual ice floes. GPS techniques are now feasible to monitor ice velocity at very high accuracy (e.g., MacMahan et al., 2009). Spatial scaling is very important for practical applications, since it is connected to forces that can act on structures. Temporal scaling is connected to short term (1 day) and very short term (1 hour) local forecasting problems for ship route planning, oil platforms, oil spills and ice pressure on ships.

In this work the frequency spectrum of sea ice drift is examined based on theoretical analysis of the equations of ice dynamics and on observations. The purpose is to combine theoretical 
analysis and ideal models with ice motion data to obtain a better understanding of the velocity spectrum of drift ice. We consider the structure and shape of the spectra and spectral response to forcing. First, the theory of sea ice drift is briefly introduced based on Leppäranta (2011). It is then extended to examine the ice velocity frequency spectrum. Then observed spectra, covering frequencies from synoptic time scales up to more than one cycle per hour, are analysed, and their correspondence with theory is discussed. The shape and level of observed ice velocity spectra can be well understood with the existing theory down to frequencies of about $1 / 3$ cycle per hour.

\section{Sea ice dynamics theory and models}

\subsection{General laws}

The present knowledge of the structure and mechanics of drift ice was developed during the twentieth century. The linear theory was produced by several authors (Nansen, 1902; Ekman, 1902; Rossby and Montgomery, 1935; Zubov, 1945; Nikiforov, 1957; Laikhtman, 1958; Doronin and Kheisin, 1975), and the nonlinear contribution was given by the AIDJEX (Arctic Ice Dynamics Joint Experiment) sea ice team in the 1970s (Coon, 1974; Coon et al., 1974). Since then satellite remote sensing has brought much new information, in particular in sea ice kinematics (Kwok et al., 1990; Agnew et al., 1997). Numerical models have made great progress (Hunke and Dukewicz, 1997; Coon et al., 1998; Girard et al., 2009), and ice-ocean and ice-atmosphere interaction have become much better understood (Andreas, 1998; McPhee, 2008). But the fundamental theory of sea ice dynamics holds much as it was in the 1970s. It has gained support from observations and its applicability has been widened, but 
detail field and remote sensing observations have also shown deficiencies in this theory (see Leppäranta, 2011).

The general system of equations of drift ice dynamics consists of the equation of motion and ice conservation law:

$$
\begin{aligned}
& \rho h\left(\frac{\partial \boldsymbol{u}}{\partial t}+\boldsymbol{u} \cdot \nabla \boldsymbol{u}+f \boldsymbol{k} \times \boldsymbol{u}\right)=\nabla \cdot \sigma+\tau_{a}+\tau_{w}-\rho g h \nabla \xi \\
& \frac{\partial J}{\partial t}+\boldsymbol{u} \cdot \nabla J=\psi+\phi
\end{aligned}
$$

Here $\rho$ is ice density, $h$ is mean ice thickness, $\boldsymbol{u}$ is ice velocity, $t$ is time, $f$ is Coriolis parameter, $\mathbf{k}$ is unit vector vertically upward, $\sigma=\sigma(J, \varepsilon, \dot{\varepsilon})$ is internal ice stress, $\varepsilon$ is strain and $\dot{\varepsilon}$ is strain-rate, $J$ is the ice state containing the relevant material properties of drift ice, $\tau_{\mathrm{a}}$ is wind stress, $\tau_{\mathrm{w}}$ is water stress, $g$ is acceleration due to Earth's gravity, $\xi$ is sea surface elevation, $\psi$ is ice state change due to mechanical deformation, and $\phi$ is ice state change due to freezing and melting. Internal stress is related to the deformation of the continuum, while stress divergence contributes to the momentum balance. In the case of sea ice these forces are frictional— they consume mechanical energy in an irrecoverable manner.

Ice state should contain at least ice compactness $A$ and mean ice thickness, $J=\{A, h\}$, or a more complete ice thickness distribution (Thorndike et al., 1975). Free drift ( $\sigma \equiv 0)$ assumption is valid for $A<0.7-0.8$, but for higher compactness, a plastic flow law (Coon et al., 1974; Hibler, 1979) is employed. Then the strength of drift ice is determined by ice thickness and compactness. In floe collision models (Shen et al., 1986), valid for compactness 
less than about 0.8 or less, the strength depends also on the floe size, but the resulting internal stress remains low.

Ice-ocean or ice-atmosphere interaction take place in the boundary layer or Ekman layer of ocean or atmosphere. Assuming that the ocean depth is more than Ekman depth or the boundary layer thickness, the sea surface pressure gradient term can be determined using the geostrophic flow law: $-g \nabla \xi=f \mathbf{k} \times \boldsymbol{U}_{\mathrm{wg}}$, where $\boldsymbol{U}_{\mathrm{wg}}$ is the geostrophic current velocity (e.g., Gill, 1982; McPhee, 2008). Quadratic drag laws are normally employed for the air and water stresses on ice (Brown, 1980; McPhee, 1980, 2008):

$$
\begin{aligned}
& \tau_{a}=\rho_{a} C_{a} U_{a}\left(\cos \theta_{a} \boldsymbol{U}_{a}+\sin \theta_{a} \boldsymbol{k} \times \boldsymbol{U}_{a}\right) \\
& \tau_{w}=\rho_{w} C_{w} \mid \boldsymbol{U}_{w}-\boldsymbol{u}\left[\left[\cos \theta_{w}\left(\boldsymbol{U}_{w}-\boldsymbol{u}\right)+\sin \theta_{w} \boldsymbol{k} \times\left(\boldsymbol{U}_{w}-\boldsymbol{u}\right)\right]\right.
\end{aligned}
$$

where $\rho_{\mathrm{a}}$ and $\rho_{\mathrm{w}}$ are air and water densities, $C_{\mathrm{a}}$ and $C_{\mathrm{w}}$ are air and water drag coefficients, $\boldsymbol{U}_{\mathrm{a}}$ and $\boldsymbol{U}_{\mathrm{w}}$ are air and water velocities, and $\theta_{\mathrm{a}}$ and $\theta_{\mathrm{w}}$ are air and water turning angles. In exact terms, in Eq. (2a) wind velocity should be replaced by the relative velocity of wind with respect to ice velocity, $\boldsymbol{U}_{\mathrm{a}}-\boldsymbol{u}$. But since $\boldsymbol{u}<<\boldsymbol{U}_{\mathrm{a}}$, the used approximation is good. Parameterization of these drag laws was thoroughly examined in AIDJEX programme in the 1970s (Brown, 1980; McPhee, 1980).

The system of equations of sea ice dynamics (Eqs. 1a, b) contains three time scales. The immediate response is determined by the time scale of ice inertia:

$$
T_{I}=\frac{H}{C_{w} U}
$$


where $H$ and $U$ are the ice thickness and velocity scales, respectively. Since $H \sim 1 \mathrm{~m}, U \sim 0.1$ $\mathrm{m} \mathrm{s}^{-1}$, and $C_{\mathrm{w}} \sim 5 \cdot 10^{-3}$ (McPhee, 1980), we have $T_{\mathrm{I}} \sim 1 / 2 \mathrm{~h}$. The second time scale is given by the pendulum day $2 \pi f^{-1}$, which is about $14 \mathrm{~h}$ in the Baltic Sea and about $17 \mathrm{~h}$ in the Sea of Okhotsk, and the third time scale is the deformation time scale, which can be taken as the inverse of strain rate magnitude, in the seasonal sea ice zone $\mid \dot{\varepsilon}^{-1} \sim 10$ days. Timescale of ice inertia is determined by the ice--water drag force, pendulum day is determined by the Coriolis acceleration, and deformation time scale is determined by the ice strength. Clearly we have

$$
T_{I}<<2 \pi f^{-1}<<|\dot{\varepsilon}|^{-1}
$$

Inertial timescale of very thin ice (less than $10 \mathrm{~cm}$ ) is down to 5 minutes, and in the Central Arctic the deformation time scale is up to 100 days. Inertial timescale is proportional to the thickness of ice, while deformation time scale is related to thickness via ice strength.

The dynamics of sea ice is strongly coupled with the dynamics of the oceanic boundary layer (OBL) beneath. In the linear theory, advection is ignored and ocean current velocity can be split into geostrophic and Ekman flow parts (e.g., Gill, 1982; McPhee, 2008), $\boldsymbol{U}_{\mathrm{w}}=\boldsymbol{U}_{\mathrm{wg}}+\boldsymbol{U}_{\mathrm{wE}}$. The former part is obtained from large-scale geostrophic dynamics, while the latter part is closely coupled with ice:

$$
\begin{aligned}
& \frac{\partial \boldsymbol{U}_{w E}}{\partial t}+f \boldsymbol{k} \times \boldsymbol{U}_{w E}=\frac{\partial}{\partial z}\left(K_{v} \frac{\partial \boldsymbol{U}_{w E}}{\partial z}\right)+K_{H} \nabla^{2} \boldsymbol{U}_{w E} \\
& z=0: K_{v} \frac{\partial \boldsymbol{U}_{w E}}{\partial z}=-\frac{\tau_{w}}{\rho_{w}} ; z \rightarrow-\infty: \boldsymbol{U}_{w E} \rightarrow 0
\end{aligned}
$$


where $K_{\mathrm{v}}$ and $K_{\mathrm{H}}$ are the vertical and horizontal turbulent viscosities, and $z$ is the vertical coordinate.

\subsection{Linear free drift}

In free drift, the internal ice stress is ignored. It is easy to see by scaling analysis that momentum advection is practically always a small term in sea ice drift (Leppäranta, 2011, Section 5.4). In more exact terms, the ice-water drag coefficient is larger than $10^{-3}$, and the length scale in free drift is limited from below by the baroclinic Rossby radius of deformation in the OBL. Assuming $H / L<10^{-4}$, where $L$ is the length scale, the ratio of advection to icewater stress can be estimated as

$$
\frac{\rho U^{2} H / L}{\rho_{w} C_{w} \hat{U}^{2}} \approx \frac{(H / L) U^{2}}{C_{w} \hat{U}^{2}}<10^{-1} \times\left(\frac{U}{\hat{U}}\right)^{2}
$$

where $U$ is ice velocity scale, and $\hat{U}=\left|\boldsymbol{u}-\boldsymbol{U}_{w}\right|$ is the scale of ice-water velocity difference. Thus only when $\hat{U}<<U$ can advection be important; this means that ice must basically follow the surface current, with insignificant wind stress or internal friction. Sea ice drift is then solved as part of the ocean dynamics problem, and momentum advection may be important in intensive dynamics situations.

Ignoring momentum advection, free drift becomes a local problem, $\boldsymbol{u}=\boldsymbol{u}(t)$. The steady-state free drift equation can be easily solved for the ice velocity relative to the geostrophic ocean 
current, $\hat{\boldsymbol{u}}_{g}=\boldsymbol{u}-\boldsymbol{U}_{w g}$, showing that ice motion is the sum of pure wind-driven drift and geostrophic current (e.g., Leppäranta, 2011, Section 6.1). The non-steady situation can be analysed by subtracting the time derivative of geostrophic current from both sides of the free drift equation. Eq. (1a), ignoring advection and ice stress, gives:

$$
\rho h\left(\frac{d \hat{\boldsymbol{u}}_{g}}{d t}+f \boldsymbol{k} \times \hat{\boldsymbol{u}}_{g}\right)=\tau_{a}+\rho_{w} C_{w}\left|\boldsymbol{U}_{w E}-\hat{\boldsymbol{u}}_{g}\right|\left(\boldsymbol{U}_{w E}-\hat{\boldsymbol{u}}_{g}\right)-\frac{d \boldsymbol{U}_{w g}}{d t}
$$

The negative time derivative of geostrophic current becomes a driving force for $\hat{\boldsymbol{u}}_{g}$. However, the inertial time scales of ice velocity and geostrophic current differ by one order of magnitude: their ratio is $T_{\mathrm{I}} f \sim 10^{-1}$. Thus inertial ice processes can be examined with fixed geostrophic current, while for variable geostrophic current, quasi-steady ice dynamics can be assumed.

In the linear theory, a linearized drag coefficient is employed: $C_{w 1}=C_{w} \hat{U}$. Integrating Eq. (5) across the OBL, assuming horizontal homogeneity, ice and oceanic boundary layer dynamics can be written in general form as:

$$
\begin{aligned}
& \frac{d \hat{\boldsymbol{u}}_{g}}{d t}=\frac{\rho_{w} C_{w 1}}{\rho h}\left(\tilde{\boldsymbol{U}}_{w e}-\hat{\boldsymbol{u}}_{g}\right)-f \mathbf{k} \times \hat{\boldsymbol{u}}_{g}+\frac{\tau_{a}}{\rho h}-\frac{d \boldsymbol{U}_{w g}}{d t} \\
& \frac{d \tilde{\boldsymbol{U}}_{w E}}{d t}=\frac{\rho_{w} C_{w 1}\left(\hat{\boldsymbol{u}}_{g}-\tilde{\boldsymbol{U}}_{w E}\right)}{\rho_{w} D}-f \mathbf{k} \times \tilde{\boldsymbol{U}}_{w E}
\end{aligned}
$$

where $D$ is sea depth and $\tilde{\boldsymbol{U}}_{w E}$ is the vertically averaged Ekman current velocity. We have taken, for simplicity, zero turning angle in the ice-water stress formula. Forcing of this 
coupled system is by wind stress and geostrophic ocean current. Eqs. $(8 \mathrm{a}, \mathrm{b})$ form a pair of linear equations, and they can be easily solved using the elimination method (Leppäranta, 2011, section 6.3; also consult basic calculus textbooks, such as Adams, 1995). Briefly, $\tilde{\boldsymbol{U}}_{w E}$ is eliminated and then a second-order equation is obtained for $\boldsymbol{u}$. The ice velocity is then is a linear function of the forcing, and the spectrum is directly obtained from the forcing spectrum (e.g., Jenkins and Watts, 1968). The resulting spectrum $p=p(\omega)$ of the relative sea ice velocity $\hat{\boldsymbol{u}}_{g}$ is:

$$
\begin{aligned}
& p(\omega)=\frac{\lambda_{i}^{2}+\omega^{2}+f^{2}}{\left[\left(\lambda_{i}+\lambda_{w}\right)^{2}+(\omega+f)^{2}\right](\omega+f)^{2}} p_{F}(\omega) \\
& \lambda_{i}=\frac{\rho_{w} C_{w 1}}{\rho_{i} h}, \lambda_{w}=\frac{C_{w 1}}{D}
\end{aligned}
$$

where $\omega$ is frequency, $\lambda_{\mathrm{i}}$ and $\lambda_{\mathrm{w}}$ are ice and Ekman layer inverse response times, respectively, and $p_{\mathrm{F}}(\omega)$ is the spectrum of the forcing. The spectrum can be expressed as $p=a p_{\mathrm{F}}$, where $a=$ $a(\omega)$ is the spectral modulation factor; $a$ can be taken as the spectral response to white noise forcing. There is one singularity, at the Coriolis frequency $\omega=-f$. Coriolis acceleration (or "Coriolis force") acts perpendicular to the direction of ice drift, to the right in the northern hemisphere, giving rise to clockwise inertial oscillation in the ice drift (e.g., Gill, 1982).

Figure 1 shows the rotary spectrum (see Gonella, 1972) of ice drift based on the coupled iceocean model (Eqs. 8a, b). Positive (negative) frequencies describe counterclockwise (clockwise) cycles. The modulation factor $a$ is dominated by the ice response, since $\lambda_{\mathrm{i}}>>\lambda_{\mathrm{w}}$, $f$, and by the singularity at the Coriolis frequency. Asymptotically, $a(\omega) \rightarrow$ constant as $\omega \rightarrow 0$, and $a(\omega) \propto \omega^{-2}$ as $\omega \rightarrow \pm \infty$. At frequencies smaller than 0.016 cycles per hour (2.6-day 
period) the modulation factor becomes flat, and at frequencies larger than 1 cycle per hour the power law of -2 appears. The spectral density is higher in the negative side for all frequencies. One may question how the simple drag law works for high frequencies. Omstedt et al. (1996) showed that the quadratic drag force differs little from the drag force obtained directly from a 2 nd order turbulence model down to frequency of 0.25 cycles per hour (their analysis did not go to higher frequencies).

Figure 1. Spectral response of free ice drift to white noise forcing based on a coupled iceocean boundary layer model shown by rotary spectrum. Upper curve: negative frequencies; lower curve: positive frequencies. Vertical scale is arbitrary.

The full free drift spectrum can be compared with two specific cases (Figure 2): (a) Ice-only, where the ocean is passive (i.e., Eq. 8a with $\boldsymbol{U}_{\mathrm{wg}}=$ constant and $\tilde{\boldsymbol{U}}_{w E}=0$ ), and (b) Locked ice-ocean (McPhee, 1978), where the ice and mixed layer flow together (Eqs. 8a and 8b added together):

$$
\begin{aligned}
& p_{i}(\omega)=\frac{p_{F}(\omega)}{\lambda_{i}^{2}+(\omega+f)^{2}} \\
& p_{i w}(\omega)=\frac{1}{(\omega+f)^{2}} \cdot\left(\frac{\rho h}{\rho h+\rho_{w} D}\right)^{2} p_{F}(\omega)
\end{aligned}
$$

respectively. The factor in parenthesis in Eq. $(7 b)$ is due to that much larger mass is driven in locked ice-OBL case; it is of the order of $10^{-3}$. Both peak at $\omega=-f$, but the peak is very weak in the ice-only case. They both decay as $\omega^{-2}$ when $\omega \rightarrow \pm \infty$. The ice response time dominates the ice-only spectrum, and the red band starts at the frequency of about 0.3 cycles per hour. In the locked ice-OBL case, Coriolis frequency dominates. The spectrum is similar to the 
coupled case but the level of variance is much lower. An ice model with 'inertial embedding' was presented by Heil and Hibler (2002). Sea ice velocity is extracted from the locked iceocean velocity by assuming a drag coefficient and a turning angle. The stationary solution is correct, and therefore low frequencies are reproduced very well in the ice velocity spectrum. Also the inertial peak comes out well but at higher frequencies the spectrum falls off too fast.

Figure 2. Sea ice velocity spectra normalized by forcing, from top down ice-ocean coupled model, ice only model, and locked ice-ocean model: (a) Negative frequencies, (b) Positive frequencies. Latitude is $60^{\circ} \mathrm{N}$, where Coriolis period is $13.9 \mathrm{~h}$.

The obtained spectra are based on the linear theory. Next we consider how the nonlinearities in free drift may influence on the spectrum of ice velocity. The full equation (Eqs. 1a and 2b) has two nonlinear terms: momentum advection and ice-water stress. The former would transfer energy to higher frequencies — as usually in turbulent flow-but it is a very small term in sea ice dynamics. In free drift driven by intensive ocean dynamics advection can become important but then the ice essentially traces ocean currents (see Eq. (6) and discussion there). Ice-water stress is well approximated by a quadratic law but the dependency is of the form $\tau_{w} \propto|\hat{\boldsymbol{u}}| \hat{\boldsymbol{u}}$, which transforms the form of a forced sine wave for sea ice velocity but does not influence on the frequency (Figure 3). In the quadratic case, ice responds faster to changes in forcing than in the linear case.

Figure 3. Simulated time series of free drift ice velocity for quadratic and linear water drag forced by a sine wave. Horizontal scale is in seconds, vertical in $\mathrm{m} \mathrm{s}^{-1}$. Drag law parameters have been tuned to give the same ice velocity amplitude in both cases. 


\subsection{Drift in the presence of internal stress}

Internal stress in drift ice is due to interaction between ice floes (see, e.g., Leppäranta, 2011, Chapters 4 and 7). Plasticity of drift ice is characterized by high compressive strength and low tensile strength and sensitivity to ice compactness (Coon et al., 1974). Also drift ice is strain hardening under compression but becomes unstable in shear.

In general, internal stress ranges from stress-free state to plastic flow (e.g., Leppäranta, 2011, Section 7.1). The effect on motion therefore ranges from zero in free drift to dominant when stress is on the yield surface. We can examine the range of rheologies by a family of viscous models:

$$
\sigma=g_{n}\left(\dot{\varepsilon}_{I}, \dot{\varepsilon}_{I I}\right) \dot{\varepsilon}, n \geq-1
$$

where $g_{\mathrm{n}}$ is n'th degree homogeneous function (i.e., $\left.g_{\mathrm{n}}(a x, a y)=a^{\mathrm{n}} g(x, y)\right)$, and $\dot{\varepsilon}_{I}$ and $\dot{\varepsilon}_{I I}$ are strain-rate invariants equal to the sum and difference of the principal strain rates. At compactness $\sim 0.8$, stress is transferred by collisions between ice floes, and the resulting rheology is super-linear, $n=1$ (Shen et al., 1986); however, the resulting stresses are then small. For $n=0$, a linear viscous law results, while for $-1<n<0$ we have sub-linear viscous laws approaching a plastic law as $n \rightarrow-1$. For a harmonic velocity component $u=u(x$, $y) \exp (-i \omega t)$, the acceleration has frequency $(n+1) \omega$, and the internal friction is comparable to the acceleration. If $n<0(n>0)$, kinetic energy is transferred toward lower (higher) frequencies, while for $n=0$ the system is linear and no cross-frequency energy transfer takes place. 
Thus in sub-linear viscous flow, kinetic energy is transferred from higher to lower frequencies. In the case of drift ice, however, the rheology possesses asymmetry in that there is strong resistance to compression but very small resistance to tension. Coupling the ice conservation and momentum equations introduces some interesting features. Since the ice stress is nonzero only during convergence, the frequency of an opening/closing cycle is transferred to the ice velocity spectrum. Thus, for any $n$ is the ice moves, its velocity is forced into the deformation frequency, and deformation frequency follows the forcing frequency. Summer and winter ice velocity spectra from the Arctic Ocean illustrate the influence of the internal stress (Thorndike and Colony, 1980); the summer situation is closer to free drift while in winter, internal stress is important. The spectra look similar, and the main differences are that in winter the overall level of spectral density is one order of magnitude lower and the semidiurnal peak is weak. There is no indication of cross-frequency energy transfer due to internal stress.

Consider a one-dimensional channel closed at one end (see Leppäranta, 2011, Section 7.2). Assume that the wind blows toward the channel end with small, cyclic variation around the mean. Then the ice will move toward the closed end but less during each wind cycle until it finally stops. The steady state situation is a stationary ice field. The ice velocity spectrum has a peak at the wind frequency and the height of the peak goes to zero with time due to the strain hardening of the ice field. In coastal shear flow (see Leppäranta and Hibler, 1985) a steady oscillating plastic flow solution is possible as $v=a\left|\boldsymbol{U}_{\mathrm{a}}\right|$, where the coefficient $a$ is a non-linear function of the wind direction. Again, the ice motion follows the wind frequencies. In both channel flow and shear flow cases, however, the behaviour of ice motion is unclear at very high frequencies where neither observations nor detailed model studies are available. Thus we must ask to how high are frequencies for which the above results are valid. 
To examine the spectra of ice velocity in the presence of internal stress, a series of numerical experiments was performed by Leppäranta et al. (2009). Ice response was simulated with an oscillating wind in a rectangular basin. Wind speed was constant but the direction turned clockwise one cycle in a given periods. Different periods were used in a number of simulations. The Hibler (1979) viscous-plastic rheology was employed. Phase shift followed the forcing but no change in the frequency space was observed. However, there was a limitation in these experiments because the momentum advection term was ignored.

The above more or less heuristic reasoning based on the theory of sea ice drift suggests that in the presence of internal stress the frequency of ice drift follows the forcing frequencies but amplitude response is highly nonlinear. No observational evidence contradicts this. However, at very high frequencies the situation is unclear due to lack of accurate observed drift data.

\section{Observations}

\subsection{Data collected}

Many observation programmes have been performed on sea ice kinematics, and, consequently a number of papers have been published on ice velocity time series analyses (e.g., Hibler et al., 1974; Ono, 1978; McPhee, 1980; Thorndike and Colony, 1980; Leppäranta, 1981; Hutchings and Hibler, 2002; Schevchenko et al., 2004; Geiger and Perovich, 2008). Here ice motion data from two different kinds of basins are used to extend the empirical knowledge toward higher frequencies and to compare the observed spectra of ideal models. 
Observations of ice motions from the Baltic Sea and Sea of Okhotsk are used. These basins are located in the seasonal sea ice zone; the thickness of ice is of the order of half meter. The latitudes of the sites are close to $65^{\circ} \mathrm{N}$ in the Baltic Sea site and $45^{\circ}-50^{\circ} \mathrm{N}$ in the Sea of Okhotsk. The data, collected in field experiments in 2005 (Sea of Okhotsk) and 2009 (Baltic Sea), include both Lagrangian and Eulerian velocities. They were obtained from drifting stations, drift buoys and Acoustic Doppler Current Profiler (ADCP). Figure 4 shows maps of the drift paths. In the Sea of Okhotsk, one buoy was drifting close to an ADCP mooring site and consequently simultaneous Eulerian and Lagrangian velocities were obtained.

In the Baltic Sea the ice season lasts on average seven months with the northern basins freezing over in normal years (Leppäranta and Myrberg, 2009). The surface area is $0.40 \cdot 10^{6}$ $\mathrm{km}^{2}$ average depth of the Baltic Sea is $54 \mathrm{~m}$. Strong winds blow mainly from southwest to west directions. Water circulation is wind-driven with weak permanent currents, and consequently sea ice dynamics is primarily wind-driven. The Sea of Okhotsk is a much larger basin (surface area $1.5 \cdot 10^{6} \mathrm{~km}^{2}$ and mean depth $838 \mathrm{~m}$ ), and the ice season coverage is 60 $75 \%$ of the total area at its annual maximum. Sea ice drift is driven by wind, permanent current system and tides. The permanent water circulation contains a basin-wide gyre with warm Soya current flowing east along the northern coast of Hokkaido. The tides are dominated by the diurnal constituents.

Figure 4. The drift data. (a) Baltic Sea drifting stations S2 and S3, March 2009. Ice chart is shown on the background map (width $290 \mathrm{~km}$ ) and drift paths enlarged in the rectangles (long sides $20 \mathrm{~km})$.

(b) Sea of Okhotsk drift buoys \#4-6 and ADCP mooring site ( $\times$ ), winter 2005, shown on map of the southern Sea of Okhotsk. 
Lagrangian velocities have been obtained by first-order differencing of positions. Assuming positioning error to be white noise with variance $\sigma_{e}^{2}$, the velocity error becomes blue noise with variance spectrum

$$
\sigma^{2}(\omega)=\frac{\sigma_{e}^{2}[1-\cos (\omega \delta t)]}{\pi \delta t}, 0 \leq \omega \leq \frac{\pi}{\delta t}
$$

where $\omega$ is frequency and $\delta t$ is the observation time interval. Especially good positioning accuracy is needed to obtain the very high frequency spectra of sea ice velocity. GPS noise decreases at high frequencies (Hutchings and Hibler 2008; MacMahan et al. 2009) and thus the white noise assumption above is a conservative underestimate of the GPS accuracy. Eulerian velocities are included in the ADCP data directly, and their error can be taken as white noise with variance depending on the instrument.

The Baltic Sea data are from a field campaign aboard R/V Aranda in March 2009 in the northern basin, the Bay of Bothnia. Ice motion has been obtained from positions of the ship moored to ice. Furuno Differential GPS was used for this, its accuracy according to the manufacturer is better than $5 \mathrm{~m}$; thus we take $5 \mathrm{~m}$ to represent the accuracy as twice the standard deviation of error. The positions were recorded at every 10 seconds and averaged over 5-minute intervals, and ice velocity was determined from these average positions at the same intervals. The time series of two drifting stations (S2 and S3) were taken for the present analysis (see Figure 4a).

In the Sea of Okhotsk, three GPS buoys (\#4, \#5 and \#6) were deployed on sea ice on the coastal 
zone at Hokkaido. The location of the buoys was recorded every hour, with positioning accuracy of $10 \mathrm{~m}$. Two (\#5 and \#6) stayed close to each other in the vicinity of Hokkaido coast, although Buoy \#5 drifted south through a strait in Kuril Islands. Buoy \#4 drifted further out from the coast and stayed in the southeastern part of the Sea of Okhotsk. After drifting nearly two months it was about $400 \mathrm{~km}$ northeast from Hokkaido. Buoys No. 5 and 6 remained close to the coast of Hokkaido during the entire time.

During the ice drift experiment an ADCP (RD Instruments WH-Sentinel 300kHz) was moored in the proximity of the north coast of Hokkaido (position $44^{\circ} 28.3^{\prime} \mathrm{N}, 143^{\circ} 25^{\prime} \mathrm{E}$, depth $48 \mathrm{~m}$ ). The ADCP was, using bottom tracking, measuring the Eulerian velocity of ice drifting over the mooring site with sampling interval of 15 minutes. Single ping standard deviations were $0.7,1$, and $1.5 \mathrm{~cm}$ for speeds of 1,3 , and $5 \mathrm{~m} \mathrm{~s}^{-1}$. Using the first value and bottom-track ping, the accuracy of velocity is $0.22 \mathrm{~cm} \mathrm{~s}^{-1}$. For the spectral analyses $1 \mathrm{~h}$ average velocities were used. ADCP was deployed for over 2.5 months, from 6 January through 25 March 2005; however it provides ice velocity measurements only when ice is present above the instrument. Since the ice concentration in the southern Sea of Okhotsk varies greatly over a few days, continuous ice velocity time series exist only for duration of 3-7 days. Buoy \#6 drifted most of the time in the proximity of the ADCP, and the data that it collected less than $100 \mathrm{~km}$ away from the ADCP mooring site is used for the comparison of Eulerian and Lagrangian frequency spectra.

\subsection{Ice velocity spectra from drifter data}

The spectral calculations were performed with MatLab software using the Welch method. In the Baltic Sea case, Hann window was used on the 5-minute interval data. Segment length 
was 120 measurements and segment overlap was $75 \%$. In the Sea of Okhotsk case, the time series were divided into 5 days long overlapping segments ( $75 \%$ overlap) and the segments were weighted using Kaiser-Bessel window. Due to the shortness of the segment needed to increase the statistical reliability, the low frequency threshold is $0.2 \mathrm{cpd}$. However, this enables the distinction between diurnal tidal, Coriolis and semidiurnal tidal responses with periods of $24 \mathrm{~h}, 16.9 \mathrm{~h}$ (latitude $45^{\circ} \mathrm{N}$ ) and $12 \mathrm{~h}$, respectively. The spectral resolution is anyhow insufficient for the separation of main diurnal tidal constituents, K1 and O1. To have good outcome for confidence intervals, different weighting windows were used because of the large differences in the lengths of the individual time series. The confidence intervals plotted in the spectra were provided automatically by MatLab software.

First, consider the basic structure of sea ice velocity spectra. In the Baltic Sea ice velocity spectra are dominated by synoptic frequencies (Leppäranta and Omstedt, 1990). Here the focus is on frequencies higher than one cycle per day. Figure 5 shows spectra from the Baltic Sea together with the corresponding wind spectra (wind velocity has been scaled by the factor of 0.02 to represent linear free drift approximation). Station S3 represents free drift while in Station S2 strong pressure was observed in the drifting ice (see Figure 4a). The difference between the spectra of S2 and S3 is, however, small: S2 has higher level at frequencies higher than 0.1 cycles per hour (cph), while at lower frequencies the situation is opposite. Wind, on the other hand, shows similar spectral characteristics in both cases.

Coriolis or inertial oscillation $(0.075 \mathrm{cph})$ is not present in these spectra although the free drift theory includes a singularity at this frequency (see Eq. 9). This oscillation develops in the ocean boundary layer and from there it is fed into ice drift. In this basin inertial oscillations are weak in winter because of frictional damping by bottom friction due to shallow depth and 
lack of stratification, although in summer inertial oscillations show up well (Leppäranta and Omstedt, 1990). Internal friction of ice also damps the Coriolis acceleration (Thorndike and Colony, 1980), but the present data support the bottom friction as the main factor.

The spectra are falling down from the synoptic scales, and through 0.1 to $0.5 \mathrm{cph}$ the fall is steepest with slope quite close to $-5 / 3$. This is inherited from the atmospheric and oceanic boundary layers, and tells of wind acting as the driving force since the spectral level of the ice velocity is close to the level of $2 \%$-wind. Interestingly, in the presence of internal stress (Station S2) ice drift is below $2 \%$-wind up to $0.15 \mathrm{cph}$ but thereafter above, while the free drift case (Station S3) is slightly below 2\%-wind at high frequencies; however, these features are too weak for firm conclusions.

Figure 5. Ice velocity spectra (solid lines) and corresponding wind spectra (dashed lines) for the drifting stations S2 and S3 in the Baltic Sea, winter 2009. The ice velocities are based on $\mathrm{R} / \mathrm{V}$ Aranda moored to ice floe.

In the Sea of Okhotsk, although the drifting paths of the buoys separated and the buoys drifted in distinct regions with different ice and oceanographic conditions (Figure 4b), their mean velocities varied only slightly, between $25-29 \mathrm{~cm} / \mathrm{s}$. In February 2005 all the buoys were located in compact ice fields with concentrations of $80-100 \%$. After a few days, ice concentration decreased and the buoys started to diverge. Later on, ice concentration varied strongly, but generally the highest concentrations occurred close to the northeast coast of Hokkaido and along the north coast of Kuril Islands. During the nearly 2 month period of ice drift, the wind speed was generally weak, exceeding $8 \mathrm{~m} / \mathrm{s}$ only twice, although it varied strongly. 
Figure 6 shows ice velocity spectra from the Sea of Okhotsk based on three drift buoys in winter 2005. The spectral range from 0.1 to 5 cycles per day (cpd) is above the measurement noise. Compared with the Baltic Sea, there are similarities and differences. In low frequencies there are more variations in the Sea of Okhotsk due to current and tidal systems. The spectral slope above synoptic frequencies is similar but in the Sea of Okhotsk tidal and Coriolis signals are seen. Diurnal tide gives a strong and wide peak, and inertial (Coriolis) oscillations (1.41 cpd) can also be identified. The presence of inertial signal in this region was shown by Ono (1978). Semidiurnal tide is not clear. In frequencies higher than $1 \mathrm{cpd}$ the spectra fall down at about the slope of $-5 / 3$ up to $5 \mathrm{cpd}$ as in the Baltic Sea. Here higher frequencies are not available.

Figure 6. Ice velocity spectra for three drift buoys from the Sea of Okhotsk, winter 2005: Buoy \#4 (blue), Buoy \#5 (red) and Buoy \#6 (green). Buoy \#4 drifted in southeastern Sea of Okhotsk and Buoys \#5 and \#6 were close to Hokkaido coast. Short error bar is for \#4 and \#5, longer one for \#6. The spectra are above the measurement noise up to about $5 \mathrm{cpd}$.

\subsection{Very high frequencies}

In sea ice dynamics it is convenient to define 'very high frequencies' by the frequencies where the inertia of ice plays an important role. Scaling the equation motion, it is seen that the importance of inertia is characterised by the Strouhal number $\mathrm{Sr}=U T / H$ (see Leppäranta, 2011), which provides the inertial time-scale as shown in Eq. (3), $T_{\mathrm{I}}=H /\left(C_{\mathrm{w}} U\right) \sim 1 / 2 \mathrm{~h}$. We

can take the band of very high frequencies to start from somewhat below $T_{\mathrm{I}}^{-1}$. To examine these frequencies requires excellent measurement accuracy, such as there is in the present Baltic Sea data. Hourly velocity fluctuations are of the order of $1 \mathrm{~cm} \mathrm{~s}^{-1}$, which cause displacements up to $36 \mathrm{~m}$ in one hour. The positioning accuracy should be at least an order of 
magnitude better. With accuracy of $5 \mathrm{~m}$ or better in the Baltic Sea drifting stations, the present work has acceptable accuracy, although still one order of magnitude better would be desirable. The present accuracy is enough to produce spectra up to a little above $1 \mathrm{cph}$.

Above the frequency of $0.1 \mathrm{cph}$, the Baltic Sea spectra first fall following the $-5 / 3$ power law (Figure 5). Then the slope changes at about $0.5 \mathrm{cph}$. At higher frequencies the spectral density is flatter, falling weaker than power law of -1 . The change in the power reflects changing in the dynamics of ice from quasi-steady drift under air-ocean forcing to a nonsteady ice regime. The measured ice drift spectra reach the measurement noise given by Eq. (12) above $1 \mathrm{cph}$ (Figure 5). At $0.5 \mathrm{cph}$ the measured spectra are well above the noise level. The blue form of the noise spectrum is clearly revealed at higher frequencies, coming as rising line toward higher frequencies.

In the linear free drift theory, in very high frequencies the spectral modulation factor (see Eq. 9 and the lines below it) approaches asymptotically a power law of -2 as $\omega \rightarrow \pm \infty$. This power law comes from the inertia of ice. The power of ice velocity spectrum is then equal to the sum of powers of the modulation factor and wind spectrum, asymptotically equal to $-2-$ $5 / 3=-11 / 3$ as $\omega \rightarrow \infty$. The linear theory is an idealized case and the results here suggest that features not present in the linear theory become important in high frequencies.

A remarkable feature is that the fall of ice velocity spectrum becomes weaker instead of becoming stronger as predicted by the linear free drift theory (Eq. 9). Possible reasons behind this weak slope above $0.5 \mathrm{cph}$ could be the following: (i) random shifts of ice floes due to floe-floe interactions, (ii) quadratic ice-water drag law, and (iii) shallow water waves in the water body. There is a natural variation in the drift of individual floes due to their different 
thicknesses and form drags, since free drift is determined by the drag parameters, Rossby number $U /(H f)$, and the inertial time scale. The response time in ice motion is independent of actual ice speed in the linear drag law but in the quadratic case it is inversely proportional to ice speed:

$$
T_{I 1}=\frac{H}{C_{w 1}}=\frac{H}{C_{w} \hat{U}}, T_{I}=\frac{H}{C_{w} U}
$$

where $\hat{U}$ is a fixed scaling speed to determine the linear drag coefficient. This means that in the quadratic case the response time becomes larger than in the linear case at very high frequencies resulting in the weaker fall of the velocity spectrum. The research basin, Bay of Bothnia is weakly stratified in winter, it is shallow (mean depth is $40 \mathrm{~m}$ ), and its size $100 \mathrm{~km}$ $\times 250 \mathrm{~km}$. Transverse and longitudinal shallow water waves are observed there, providing sources to force very high frequency oscillations in ice velocity; the existence of Kelvin and Poincaré waves has been hypothesized but not proved.

The band spectral power weakening is, however, rather narrow for the range it can be seen, and for frequencies higher than about $2 \mathrm{~h}^{-1}$ the spectrum is in the noise and remains unknown. Earlier published ice velocity spectra do not go into the very high frequencies and do not show clear indications of this weakening band. Also it is unclear whether the present sea ice dynamics theory can explain the phenomenon.

\subsection{Lagrangian and Eulerian spectra}


The connection of Lagrangian and Eulerian is non-trivial, and in sea ice dynamics there is also a very clear distinction in them due to the finite size of ice floes. Lagrangian dynamics follow a fixed a ice floe, which responds to forcing by its shape and drag properties, while Eulerian dynamics see different ice floes passing fixed points is space. Thus Eulerian ice velocity spectra should contain the variance due to variations in the floe characteristics and therefore should be on a higher level than the Lagrangian spectra. In free drift, the difference in the spectra shows the influence of floe characteristics exactly, but the stronger is the internal stress the more individuality of ice floes is merged into large-scale continuum floe of the ice field.

Most ice kinematics investigations are based in Lagrangian data collected by drifters and alike. Eulerian data have also been analysed (e.g., Schevchenko et al., 2004) but no simultaneous Lagrangian and Eulerian ice velocity analyses are available. The present experimental data from the Sea of Okhotsk provides both Lagrangian and Eulerian velocities in the same region and time (Figure 7). The drifter moved in the region of the mooring location. This is the first time such simultaneous Lagrangian and Eulerian spectra can be examined in sea ice kinematics. Eulerian spectra are here well above the measurement noise level (about $1 \mathrm{~cm}^{2} \mathrm{~s}^{-}$ $1 / \mathrm{cpd})$, Lagrangian is good up to the frequency of about $5 \mathrm{cpd}$.

In the observations, Eulerian spectrum is at higher level than the Lagrangian spectrum as anticipated. The difference does not show significant variations across the spectrum, but the slopes of the spectra show indication to differ at high frequencies. In this case the ice field was not compact and likely not far from free drift, and the difference in the spectra reflects to a large degree the influence of variability of ice floe characteristics. The linear free drift theory presented in Section 2.2 exactly corresponds to Lagrangian dynamics. Its modification 
into Eulerian dynamics would necessitate a two-dimensional grid with marked ice floes. In simple approach, a random forcing could be added into the free drift equation and that would then rise the Lagrangian spectrum to a higher level.

Figure 7. Eulerian (blue line) and Lagrangian (red line) ice velocity spectra from the Sea of Okhotsk. Eulerian spectrum was obtained from ADCP mooring site and Lagrangian spectrum from a drifter in the region of the mooring site.

\section{Conclusions}

In this work the frequency spectrum of sea ice drift has been examined based on theoretical analysis of the equations of ice dynamics and observations. The observations sites are from the Baltic Sea and Sea of Okhotsk, both in the seasonal sea ice zone. The former basin is shallow and ice drift is mostly wind-driven, while the latter basin is deeper with strong tidal currents. The resulting ice velocity spectra shows differences due to external forcing conditions and basin characteristics but also similarities due to invariances in ice-ocean dynamics.

Linear free drift forms the basic theoretical model, coupled with the ocean boundary layer. Ice dynamics modifies the spectrum of forcing, which is due to wind and tidal and geostrophic ocean currents, determined by relaxation time scales of ice and oceanic boundary layer and Coriolis acceleration. The modulation falls asymptotically with frequency in the power of -2 at high frequencies and contains a singularity in the inertial (Coriolis) frequency. Inertia of the ice itself shows up in frequencies higher than about 0.5 cycles per hour. Nonlinearities in free 
drift do not cause significant transfer in the frequency space. Momentum advection is a weak factor, and the quadratic ice-water stress modifies the waveform of a sine wave forcing but does not influence the frequency. Internal stress of drift ice is plastic — strongly nonlinear. The plastic rheology of drift ice is asymmetric in that it gives strong resistance to compression but weak resistance to tension. Convergence and divergence of ice tend to follow the forcing and consequently the internal friction does so, and therefore ice motion inherits the forcing frequency. In spin-up and spin-down of plastic ice drift the situation becomes more complicated.

In the observed spectra the main spectral peak is wide at the synoptic time scales, and toward higher frequencies the spectrum shows red noise with inertial and tidal signals peaking up from it. In the absence of geostrophic currents, wind dominates the ice velocity spectra at frequencies below one cycle per day. At higher frequencies, the tidal and inertial signals are commonly observed. In the red noise band, the slope is close to $-5 / 3$ from semidiurnal frequency down to $0.5 \mathrm{cph}$. In very high frequencies, above $0.5 \mathrm{cph}$ there was indication that the power of the in the spectral fall was changed from $-5 / 3$ to weaker than -1 . The reason for this was suggested to be due to nonlinearity of the ice-water interfacial stress, mechanical interactions between ice floes, or shallow water waves in the basin. One case was presented from the Sea of Okhotsk where Eulerian velocities were measured with fixed ADCP mooring and simultaneously Lagrangian measurements were collected with drift buoys in the same region. Eulerian velocity spectrum was above Lagrangian velocity spectrum over all frequencies $(0.1-5 \mathrm{cpd})$. The difference in Lagrangian and Eulerian spectra is well covered by the theory. 
The linear free drift theory can explain the observed free drift spectra with their synoptic, inertial and tidal peaks and the power law of the spectral density at high frequencies. The very high frequency remains, however, a major problem. Theory suggests that the spectral power law becomes stronger asymptotically but observations indicate that the power becomes weaker at least up to $2 \mathrm{cph}$. To solve this question needs first of all ice drift velocity observations with very high accuracy (positioning accuracy better than $1 \mathrm{~m}$ ). When internal stress becomes stronger and stronger, the velocity spectrum goes to zero everywhere as known from observations. Another problem is that how this decrease takes place across the whole spectrum. The existing empirical data does not cover this question well. Understanding the very high frequencies in sea ice dynamics is important in development of short-term forecasting method for ice forces on platforms and ships and for drift and dispersion of oil spills in ice fields.

\section{Acknowledgements}

We want to thank Dr. Robert Pritchard for most helpful comments on the manuscript. This work has been financially supported by the Academy of Finland, project Mesoscale dynamicthermodynamic modelling of sea ice (122412).

\section{References}

Adams, R.A., 1995. Calculus: A complete course, 3rd edn. Addison-Wesley, Don Mills, Ontario. 
Agnew, T.A., Le, H., Hirose, T., 1997. Estimation of large scale sea ice motion from SSM/I 85.5 GHz imagery. Annals of Glaciology 25, 305-311.

Andreas, E. L., 1998. The atmospheric boundary layer over polar marine surfaces. In: The Physics of Ice-covered Seas, Vol. 2, pp. 715-773. University of Helsinki Press, Helsinki, Finland.

Brown, R.A., 1980. Planetary boundary layer modeling for AIDJEX. In: R.S: Pritchard (Ed.), Proceedings of ICSI/AIDJEX Symposium on Sea Ice Processes and Models (pp. 387401). University of Washington, Seattle.

Coon, M.D., 1974. Mechanical behaviour of compacted Arctic ice floes. Journal of Petroleum Technology 257, 466-479.

Coon, M.D., Maykut, G.A., Pritchard, R.S., Rothrock, D.A., Thorndike, A.S., 1974. Modeling the pack ice as an elastic-plastic material. AIDJEX Bulletin 24, 1-105.

Coon, M.D., Knoke, G.S., Echert, D.C., Pritchard, R.S., 1998. The architecture of an anisotropic sea ice mechanics constitutive law. Journal of Geophysical Research 103(C10), 21,915-21,925.

Doronin, Yu.P., Kheysin, D.Ye., 1975. Morskoi led [Sea Ice]. 318 pp. Gidrometeoizdat, Leningrad [English transl. 1977 by Amerind, New Delhi].

Ekman, V.W. (1902) Om jordrotationens inverkan på vindströmmar i hafvet. Nyt Magasin för Naturvidenskab B 40, 1.

Geiger, C.A. and Perovich, D.K., 2008. Springtime ice motion in the Western Antarctic Peninsula Region (US GLOBEC contribution number 515). Deep-Sea Research II, 55, $338-350$.

Gill, A.E., 1982. Atmosphere-Ocean Dynamics. 662 pp. Academic Press, New York.

Girard, L., Weiss, J., Molines, J.M., Barnier, B., Bouillon, B., 2009. Evaluation of highresolution sea ice models on the basis of statistical and scaling properties of Arctic sea 
ice drift and deformation. Journal of Geophysical Research 114(C8).

Goldstein, R.V., Osipenko, N.M., Leppäranta, M., 2009. Relaxation scales and the structure of fractures in the dynamics of sea ice. Cold Regions Science and Technology 58, 29-35.

Gonella, J., 1972. A rotary component method for analyzing meteorological and oceanographic vector time series. Deep-Sea Research 19, 833-846.

Heil, P., Hibler, W.D., III, 2002. Modeling the high-frequency component of Arctic sea ice drift and deformation. Journal of Physical Oceanography 32, 3039-3057.

Hibler, W.D., III, 1979. A dynamic-thermodynamic sea ice model. Journal of Physical Oceanography 9, 815-846.

Hibler, W.D., III, Weeks, W.F., Kovacs, A., Ackley, S.F., 1974. Differential sea-ice drift. I. Spatial and temporal variations in sea ice deformation. Journal of Glaciology 13(69), $437-455$.

Hunke, E., Dukewicz, J.K., 1997. An elastic-viscous-plastic model for sea ice dynamics. Journal of Physical Oceanography 27, 1849-1867.

Hutchings, J. K., Hibler, W.D., III, 2008. Small-scale sea ice deformation in the Beaufort Sea seasonal ice zone. Journal of Geophysical Research 113(C8).

Jenkins, G.M. and Watts, D., 1968. Spectral analysis and its applications. Holden-Day, San Fransisco, CA.

Kheysin, D.Ye., 1978. Relationship between mean stresses and local values of internal forces in a drifting ice cover. Oceanology 18(3), 285-286.

Kwok, R., Curlander, J.C., McConnell, R., Pang, S.S., 1990. An ice-motion tracking system at the Alaska SAR facility. IEEE Journal of Oceanic Engineering 15(1), 44-54.

Laikhtman, D.L., 1958. O vetrovom dreife ledjanykh poley [On the wind drift of polar ice]. Trudy Leningradskiy Gidrometeorologicheskiy Institut 7, 129-137. 
Leppäranta, M., 1981. On the structure and mechanics of pack ice in the Bothnian Bay.

Finnish Marine Research 248, 3-86.

Leppäranta, M., 2011. The drift of sea ice, 2nd edition. 350 pp. Springer-Praxis, Heidelberg, Germany.

Leppäranta, M., Hibler, W.D., III, 1985. The role of plastic ice interaction in marginal ice zone dynamics. Journal of Geophysical Research 90(C6): 11899-11909.

Leppäranta, M., Myrberg, K., 2009. Physical oceanography of the Baltic Sea. Springer-Praxis, Heidelberg, Germany.

Leppäranta, M., Omstedt, A., 1990. Dynamic coupling of sea ice and water for an ice field with free boundaries. Tellus 42A, 482-495.

Leppäranta, M., Sun, Y., Haapala, J., 1998. Comparisons of sea-ice velocity fields from ERS1 SAR and a dynamic model. Journal of Glaciology 44(147), 248-262.

Leppäranta, M., Wang, K., Oikkonen, A., 2009. Modelling studies of the frequency spectrum of sea ice velocity. Proceedings of the 20th International Conference on Port and Ocean Engineering under Arctic Conditions, Paper \#8. Luleå University of Technology, Sweden.

MacMahan, J., Brown, J. and Thornton, E., 2009. Low-Cost Handheld Global Positioning System for Measuring Surf-Zone Currents. Journal of Coastal Research 25(3), 744-754, doi: $10.2112 / 08-1000.1$.

McPhee, M.G., 1978. A simulation of the inertial oscillation in drifting pack ice. Dynamics of Atmospheres and Oceans 2, 107 122.

McPhee, M.G., 1980. An analysis of pack ice drift in summer. In: R.S: Pritchard (Ed.), Proceedings of ICSI/AIDJEX Symposium on Sea Ice Processes and Models (pp. 62-75). University of Washington, Seattle. 
McPhee, M.G., 2008. Air-ice-ocean interaction: turbulent ocean boundary layer exchange processes. Springer, Berlin, Germany.

Marsan, D., Stern, H., Lindsay, R., Weiss, J., 2004. Scale Dependence and Localization of the Deformation of Arctic Sea Ice. Physical Review Letters 93(17).

Nansen, F., 1902. The Oceanography of the North Polar Basin. Norwegian North Polar Expedition 1893-1896. Scientific Results (Vol. III, No. 9, pp. 427 pp.). Longman Green \& Co., Kristiania, Norway.

Nikiforov, E.G. (1957) Changes in the compactness of the ice cover in relation to its dynamics. Problemy Arktiki (Vyp. 2). Morskoi Transport Press, Leningrad [in Russian].

Omstedt, A., Nyberg, L., Leppäranta, M., 1996. The role of ice inertia in ice-ocean dynamics. Tellus 48A, 593-606.

Ono, N., 1978. Inertial period motions of drifting ice. Low Temperature. Science A37, 107113.

Overland, J.E., Walter, B.A., Curtin, T.B., Turet, P., 1995. Hierarchy in sea ice mechanics: A case study from the Beaufort Sea. Journal of Geophysical Research 100(C3), 45594571.

Pritchard, R.S., 1975. An elastic-plastic constitutive law for sea ice. Journal of Applied Mechanics 42E, 379-384.

Rampal, P., Weiss, J., Marsan, D., Bourgoin, M., 2009. Arctic sea ice velocity field: General circulation and turbulent- like fluctuations. Journal of Geophysical Research, 114, C10014, doi:10.1029/2008JC005227.

Richter-Menge, J., McNutt, S.L., Overland, J.E., Kwok, R., 2002. Relating arctic pack ice stress and deformation under winter conditions. Journal of Geophysical Research 107(C10), SHE 15 (doi:10.1029/2000JC000477).

Rossby, C.G., Montgomery, R.G., 1935. Frictional Influence in Wind and Ocean Currents 
Papers in Physical Oceanography and Meteorology Vol. 3, No. 3, 101 pp. Massachusetts Institute of Technology and Woods Hole Oceanographic Institute, Cambridge, MA. Sanderson, T.J.O., 1988. Ice mechanics. Risks to Offshore Structures. 253 pp. Graham \& Trotman, Boston.

Schevchenko, G.V., Rabinovich, A.B., Thomson, R.E., 2004. Sea-ice drift on the northeastern shelf of Sakhalin island. Journal of Physical Oceanography 34, 2470-2491.

Shen, H.H., Hibler, W.D., III, Leppäranta, M., 1986. On applying granular flow theory to a deforming broken ice field. Acta Mechanica 63, 143-160.

Shuleikin, V.V., 1938. Drift of Ice Fields. Doklady Academy of Sciences USSR 19(8), 589594.

Stern, H. L., Lindsay, R.W., 2009. Spatial scaling of Arctic sea ice deformation. Journal of Geophysical Research 114(C10).

Thorndike, A.S., 1986. Kinematics of sea ice. In N. Untersteiner (Ed.), Geophysics of sea ice, pp. 489-549. Plenum Press, New York.

Thorndike, A.S., Colony, R., 1980. Large-scale ice motion in the Beaufort Sea. In: R.S, Pritchard (ed.), Sea Ice Processes and Models, pp. 249-260. University of Washington Press, Seattle.

Zubov, N.N., 1945. L'dy Arktiki [Arctic Ice]. Izdatel'stvo Glavsermorputi, Moscow [English translation 1963 by US Naval Oceanographic Office and American Meteorological Society, San Diego]. 


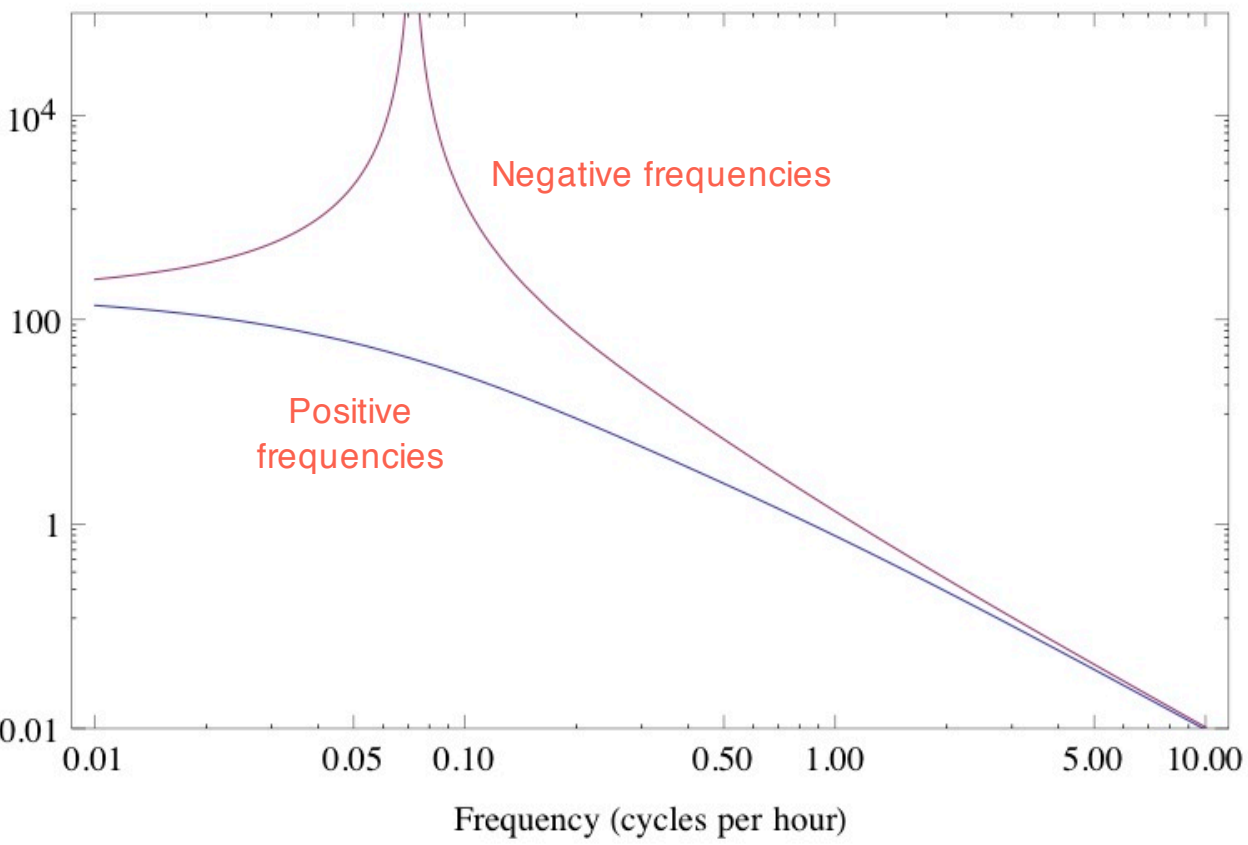




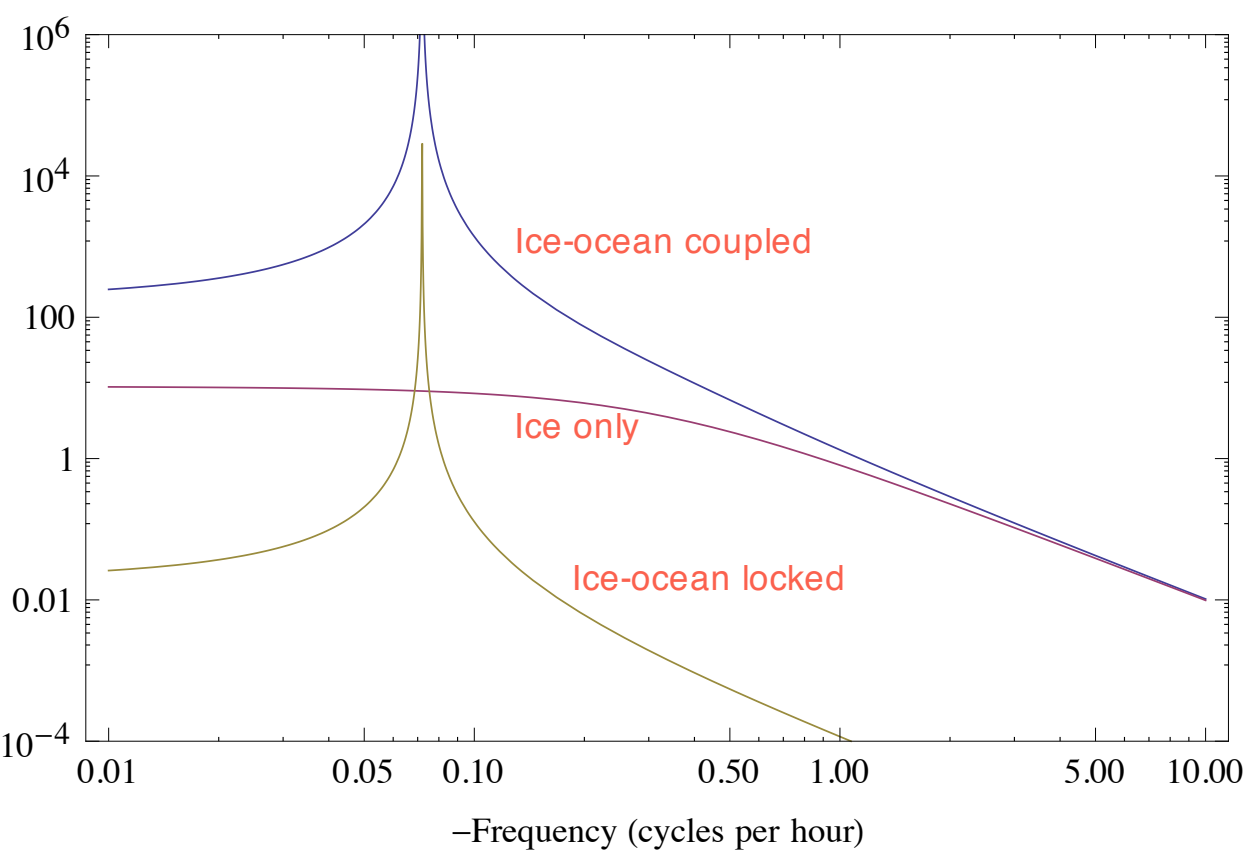




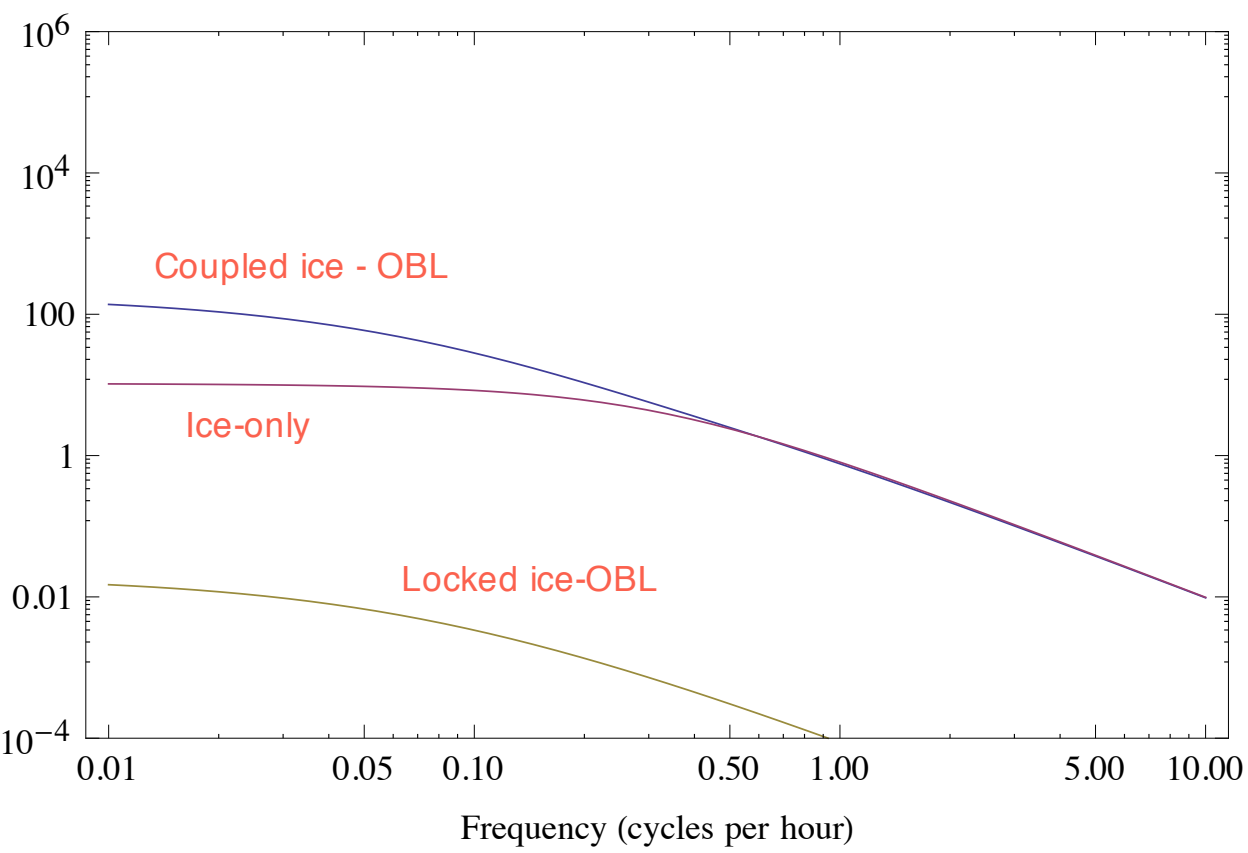




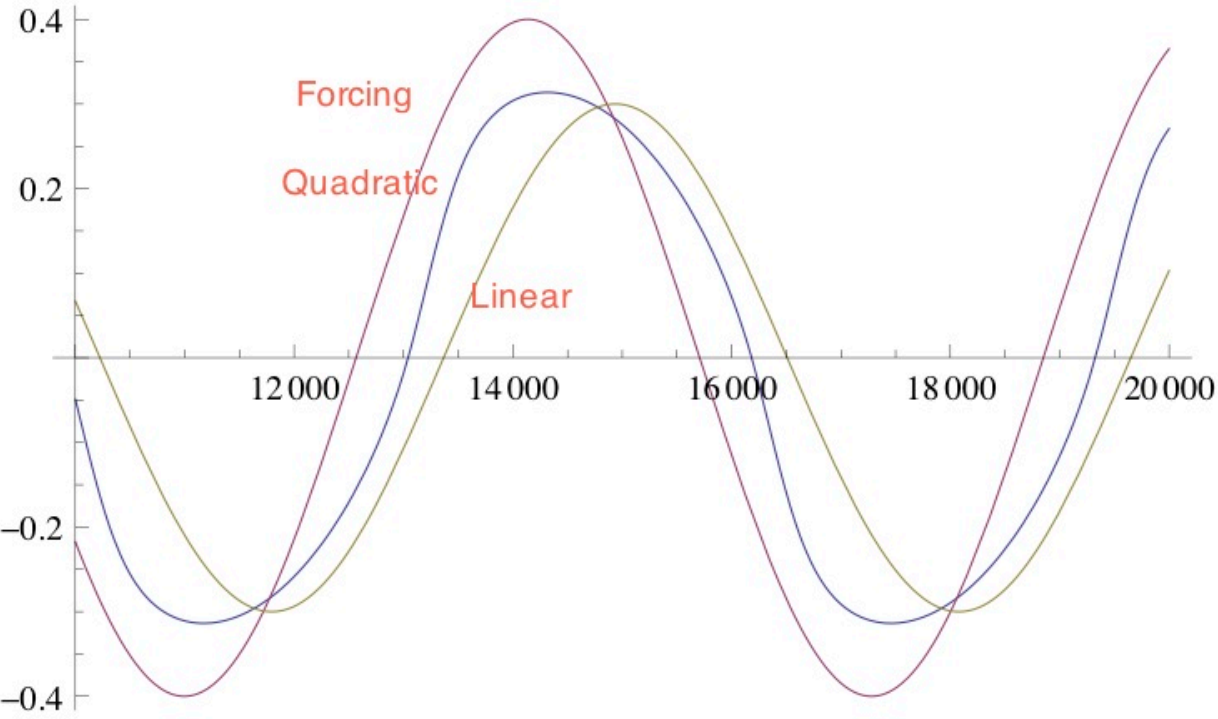




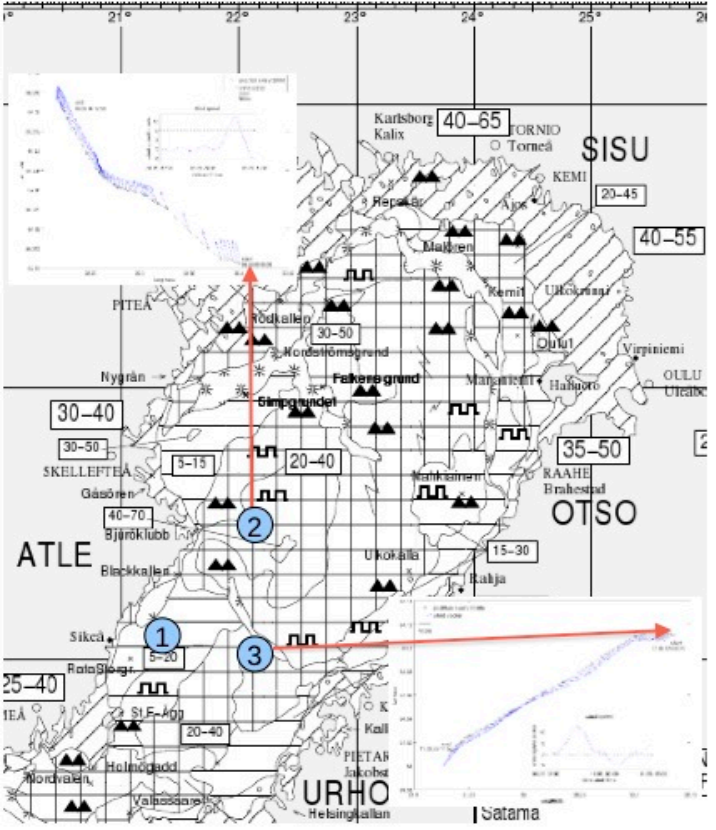




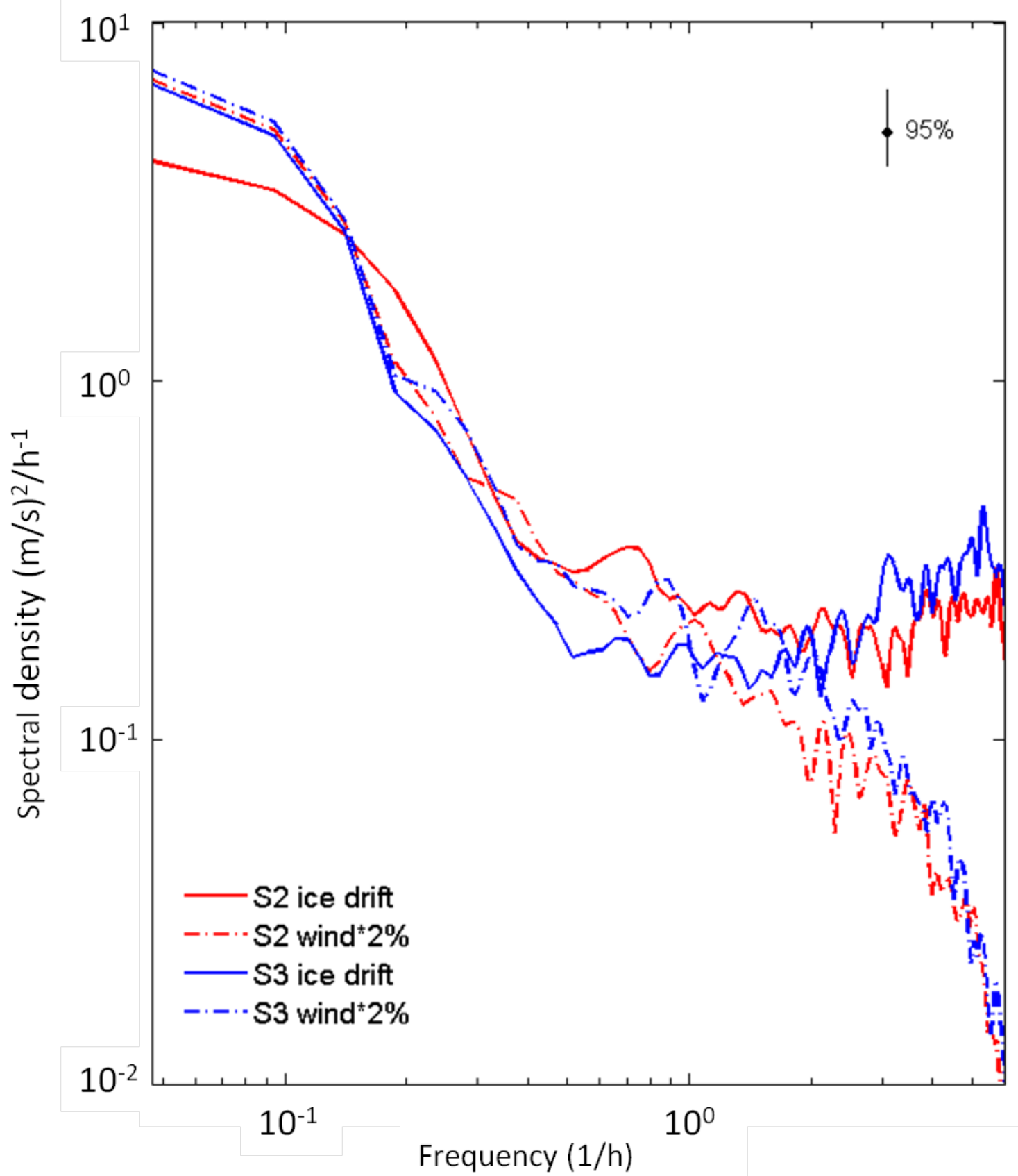




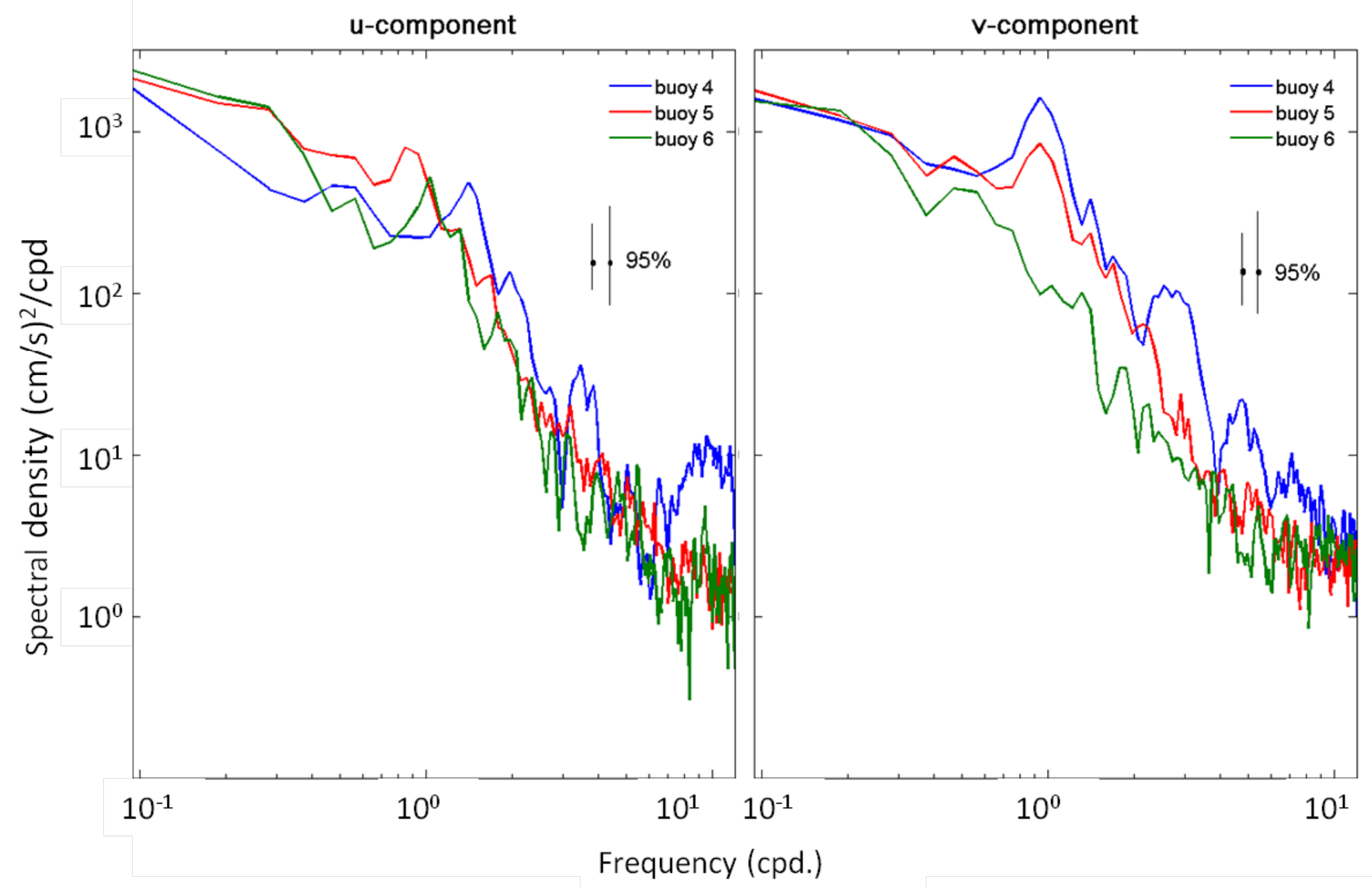




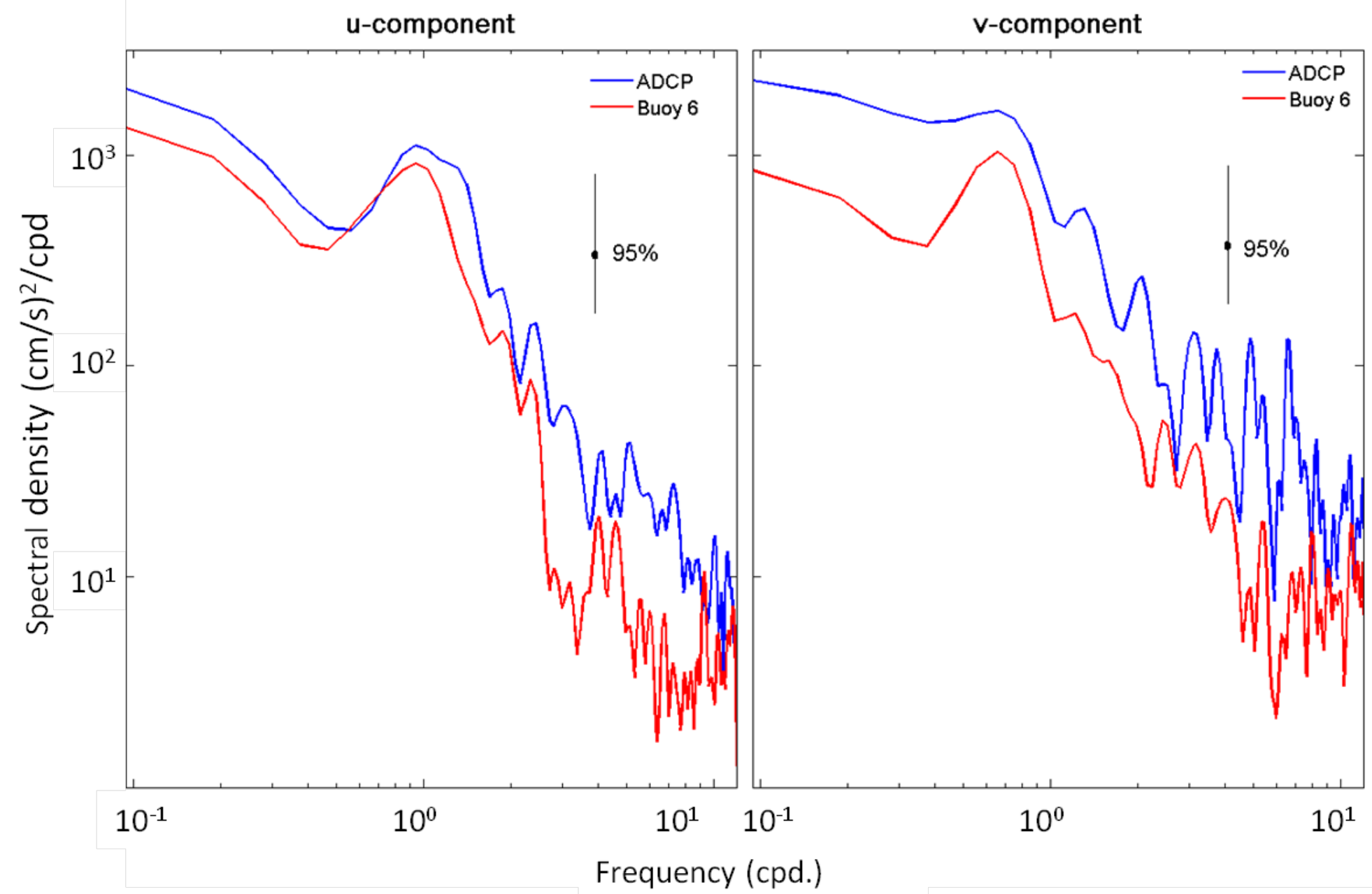

